\title{
Electrical, Thermal and Rheological Properties of Low-density Polyethylene/Ethylene Vinyl Acetate/Graphene-like Composite
}

\author{
Sohrab. Azizi ${ }^{1}$, Claudiane. Ouellet-Plamondon ${ }^{1}$, Phuong. Nguyen Tri ${ }^{1,2}$, Michel. Fréchette ${ }^{1}$, \\ Eric. David ${ }^{1 *}$ \\ ${ }^{1}$ École de Technologie Supérieure (Université du Québec), 1100 Notre Dame St. W, \\ H3C 1K3, Montréal, QC, Canada \\ ${ }^{2}$ Department of Chemistry, Montréal University, 2900 Edouard Montpetit Blvd, H3T 1J4, \\ Montreal, QC, Canada
}

\begin{abstract}
Composites of low-density polyethylene (LDPE), ethylene vinyl acetate (EVA), and a graphene-like material were explored for their electrical properties for use in high-volume lowcost conductive applications. A graphene-like material, obtained from hybrid clay-sucrose carbonization, was investigated as an alternative filler with advantages over conventional graphene technology. The electrical properties of the composites as synthesized by the solvent-casting technique were studied using broadband dielectric spectroscopy. The percolation threshold was identified for both as synthesized and annealed composite samples. Due to charge transport and electrode polarization, the sub-percolating composites exhibited low frequency dispersion particularly at elevated temperatures. Composites of LDPE/EVA/graphene-like above the percolation threshold exhibited a higher rheological storage modulus and thermal stability which indicates an alignment between the electrical, thermal and rheological properties.
\end{abstract}

Keywords: LDPE/EVA blend, electrical properties, graphene-like, rheological properties.

*Corresponding author: Email address: claudiane.ouellet-plamondon@etsmtl.ca

Department of Construction Engineering, École de Technologie Supérieure (ÉTS), Université du Québec, 1100 Notre-Dame St W, Montréal, QC H3C 1K3, Canada. 


\section{Introduction}

Polymer blend and composites have increasingly been studied for their electrical and thermal properties since the 1990s. Significant efforts have been spent to modify the existing polymers and to tailor the properties of different thermoplastics to elastomers. Several complex and novel manufacturing techniques have been used to produce desirable materials with advanced properties for electrical and thermal applications [1-5]. The method of blending polymers can provide materials with desired properties by tuning and controlling the component contents and their morphologies. From an economic standpoint, the blending process is favorable for producing low-cost products with improved qualities [6, 7]. However, in some cases, the desired properties cannot be acquired by the blending process and require the use of other additives such as fillers. Furthermore, binary and ternary polymer blends or multi-component composites can require complex processing due to component incompatibility. Coupling agents are often needed to improve the compatibility of blend components by raising interfacial adhesion and reducing surface tension with fillers [8].

Among thermoplastic polymers, polyethylene of different grades has been widely used in various industrial fields thanks to its low-cost, easy processability and properties suitable for practical functions $[9,10]$. Lowdensity polyethylene (LDPE) is a semi-crystalline polymer with a typical $40 \%$ degree of crystallinity, soluble in some nonpolar organic solvents at approximately $100{ }^{\circ} \mathrm{C}$. Polyethylene features $\alpha$, $\beta$, and $\gamma-$ relaxation occurring at different frequencies depending on the applied temperature and the morphology of the polymer. The $\alpha$-relaxation is linked to the mobility of the crystalline regions at elevated temperature, the $\beta$-relaxation ascribed to the branched ties to the main polymer chains which relax at modest temperature $\left(10{ }^{\circ} \mathrm{C}\right)$, and the $\gamma$-relaxation attributed to the crankshaft motion of amorphous regions [11-14]. These processes can be monitored in dynamic thermo-mechanical experience but are hardly seen in dielectric relaxation spectroscopy because of the non-polar nature of the polymer. Low-density polyethylene is one of the most widely-used grades of polyethylene and is known to be an insulating polymer with a relative permittivity of $2.3[15,16]$. When loaded with conductive fillers, it has been used in numerous applications, such as conductive layers in high-voltage cables, as well as, electromagnetic shielding products [17].

Ethylene vinyl acetate (EVA) as a commodity thermoplastic elastomer is widely used in biomedical engineering [18], insulating applications [19, 20] and in conductive sensors [21]. The vinyl acetate (VA) content in EVA has been reported from 15 to $70 \%$ [22]. EVA shows a glass transition temperature around $30{ }^{\circ} \mathrm{C}$ and is soluble in some aromatic solvents at high temperatures $\left(\sim 90^{\circ} \mathrm{C}\right)$. EVA features two relaxation peaks when it is subjected to an electric field, the $\alpha$ - and $\beta$-relaxation peaks. The former is related to the micro-Brownian peak (at low temperatures) due to the side groups attached to the main chain. The latter is related to the reorientation of dipoles created by segmental motions at around the glass transition 
temperature [6, 11, 23]. Mechanically, EVA copolymer is known as a soft material with an amorphous structure, which displays comparatively low stiffness and mechanical properties. In comparison with polyethylene, the permittivity of EVA is higher than the LDPE due to the VA groups which are highly polarizable, particularly at high frequencies. However, EVA features suitable dielectric strength and can be used in low and medium voltage applications [22].

Conductive inorganic additives are of great importance for the development of functional polymeric composites. Graphene is a versatile filler with a two-dimensional (2D) geometry and honeycomb crystal structure [24-30]. It is known to possess high carrier mobility of $200,000 \mathrm{~cm}^{2} / \mathrm{Vs}$ and a high thermal conductivity of $3000 \mathrm{~W} / \mathrm{m} . \mathrm{K}[31,32]$. Numerous efforts have been made to produce graphene using a variety of techniques [33-36]. The blending of commercially exfoliated graphene in EVA has been met with difficulty and has shown that higher concentrations of graphene are needed to reach the percolation threshold due to agglomeration [37]. Thus, alternative methods to produce graphene-like materials for use as fillers in polymer blends pose significant opportunity [38, 39].

The synthesis and use of graphene-like fillers at high contents remain challenging. In some cases, the obtained graphene-like material is electrically conductive enough to be used as filler in conducting composites. For instance, the conductive graphene-like filler prepared from natural resources (bentonite and sucrose) $[33,36]$ was conductive enough to increase the electrical conductivity of LDPE [10]. However, the LDPE/graphene-like composite was found to be conductive at filler content higher than $30 \mathrm{wt} \%$, where the multilayered graphene-like showed a significant agglomeration within the composite. This agglomeration is deemed to prevent the formation of the electrical network in the composite at low filler content. Furthermore, the LDPE/graphene-like composite featured a non-linear behaviour as it was subjected to several electric fields. The electrical conductivity of LDPE composites with commercial graphene and graphene-like filler were studied. It was found that the commercial graphene composites are conductive at lower filler content than the graphene-like composites due reduced agglomeration and content of oxygenated groups within the filler [40]. The LDPE composite with functionalized graphene and graphene-like filler prepared by ball-milling featured an electrical conductivity only at high filler content due to poor filler dispersion in the composites [41]. LDPE/graphene composites with few oxygenated groups attached to the graphene showed a non-ohmic behavior [42]. The EVA/reduced graphene oxide composites prepared by in situ polymerization showed an electrical conductivity of $2.7 \times 10^{-3} \mathrm{~S} / \mathrm{cm}$ upon the addition of $6 \mathrm{wt} \%$ of the filler [43]. The electric percolation threshold of EVA composite prepared by solvent-casting was reported at a loading or 17 per hundred [44].

The blending of polymers allows for the reduction of the filler content to reach electrical conductivity. The formation of a carbon-based conductive network within the composite with minimum filler content is 
desirable for maximizing the cost efficiency of the composite in large-scale applications. This strategy overcomes the limitations in filler's intrinsic properties, compounding conditions, and chemical composition of polymers. PE/EVA blend compounded with carbon black and carbon nanotubes to investigate the electrical conductivity of composites has been reported in several studies, but few studies have been conducted so far with the addition of graphene. For example, 4 wt \% carbon black (CB) filler was added to a HDPE/EVA immiscible blend, and the electrical conductivity of the composite increased from $10^{-14}$ to $10^{-3} \mathrm{~S} / \mathrm{cm}$ [45]. A percolation threshold was observed at around $15 \mathrm{wt} \%$ of $\mathrm{CB}$ content for EVA/LDPE/CB composite, for which the electrical conductivity of the composite reached $10^{-3} \mathrm{~S} / \mathrm{cm}$ [46]. To locate and disperse graphene flakes in EVA/LDPE/graphene composite, two processing methods (fast quenching and annealing) were used by Kurusu et al. [47]. The findings revealed a significant reduction in the percolation threshold for composite with respect to LDPE/graphene or EVA/graphene composites. In addition, annealing (gradual cooling down during hot press molding) was found to lower the electrical percolation threshold of EVA/LDPE/graphene composite compared to faster cooling, thanks to better graphene layered migration between polymer chains.

As the herein described graphene-like composite from sugar and clay can be produced in large quantity, the electrical, thermal and rheological properties of LDPE/EVA/Graphene-like composites were investigated for high-volume low-cost composite applications. The morphology of the as-prepared composites was first observed by scanning electron microscopy (SEM) to identify the dispersion and distribution of the graphene-like filler particles throughout the composite. Thereafter, the chemical interactions of the LDPE/EVA blend and its composites with the use of LLDPE-g-MA compatibilizer were assessed via FT-IR spectroscopy. The electrical properties of the composite were investigated by broadband dielectric spectroscopy (BDS). TGA experiments were conducted to measure the alteration of the thermal stability caused by the inclusion of the graphene-like filler as well as to assess the nominal amount of filler. The effect of the filler content on crystallinity, as well as the melting point of the composite was studied to corroborate the role of local changes on overall properties of the composites. Finally, the rheological behaviors of the composite in the molten state were investigated to obtain a comprehensive view regarding the role of the fillers in the composite.

\section{Materials and processing}

Low-density polyethylene (LDPE) powder used for this study was purchased from Marplex Company with a density of $0.922 \mathrm{~g} / \mathrm{cm}^{3}$ and a melt flow index of $0.4 \mathrm{~g} / 10 \mathrm{~min}$. Ethylene vinyl acetate copolymer (EVA) was obtained from Repsol Company with $28 \%$ VA content and a density of $0.950 \mathrm{~g} / \mathrm{cm}^{3}$. Xylene and toluene were supplied from Sigma-Aldrich Company with $99.5 \%$ purity. Linear low-density polyethylene grafted maleic anhydride, LLDPE-g-MA, was provided from DuPont (Fusabond M603) 
company. All purchased materials were used as received. Graphene-like filler was produced in the university's laboratories from natural resources (clay and sucrose). The fabrication process is described in detail in the literature [36]. In summary of this process, one part of bentonite clay and five parts of sucrose were mixed. Each gram of bentonite and sugar was dissolved in 1.2 and $0.5 \mathrm{ml}$ of demineralized water, respectively. Mixing was conducted at $400 \mathrm{rpm}$ mixing speed for $20 \mathrm{~min}$ and the obtained caramel-clay was kept in an oven for a week at $50{ }^{\circ} \mathrm{C}$. Finally, the mixture was heated in a furnace at $800{ }^{\circ} \mathrm{C}$ and the assynthesized monolith was ground to a micro-size filler.

\subsection{Sample preparation}

$\mathrm{LDPE} / \mathrm{EVA} / \mathrm{G}_{\mathrm{x}}(\mathrm{x}=$ graphene $\mathrm{wt} \%)$ composites were produced using the solvent casting method with a range of graphene-like filler contents (see Table 1). Solvent casting technique was selected for better filler dispersion. Annealing (A) and non-annealing (NA) steps were applied during hot press molding and the samples are labeled accordingly. LDPE and EVA were respectively dissolved in xylene and toluene solvent at high temperate $\left(90^{\circ} \mathrm{C}\right)$. LLDPE-g-MA compatibilizer was added to LDPE during dissolution. Graphenelike filler was mixed in the solution and then, the dissolved blends and suspended graphene-like filler were compounded using $600 \mathrm{rpm}$ stirring at $90{ }^{\circ} \mathrm{C}$ for 2 hours. Afterwards, the compounded viscous materials were subjected to ultrasonic mixing $(1 \mathrm{~min})$ with a Qsonica sonicator (Q700). The prepared composites were dried on an aluminum foil until no more changes in weight were observed. The composites were then pelletized using a Brabender pelletizer. Subsequently, the annealed composite disks were fabricated by hot press molding at $155^{\circ} \mathrm{C}$ and $7 \mathrm{MPa}$ load for $5 \mathrm{~min}$ and then, while the same load was maintained, cool down to room temperature gradually. The non-annealed composites were molded at $0.8 \mathrm{MPa}$ at $155^{\circ} \mathrm{C}$ for 2 hours and then quenched in tap water. The density of the LDPE/EVA blend and corresponding composites was measured using an ethanol pycnometer.

Table 1. Composites labelling according to the component concentration

\begin{tabular}{lccccc}
\hline \multicolumn{1}{c}{ Sample } & $\begin{array}{c}\text { LDPE } \\
(\text { wt } \%)\end{array}$ & $\begin{array}{c}\text { EVA } \\
(\text { wt } \%)\end{array}$ & $\begin{array}{c}\text { Graphene-like } \\
(\text { wt } \%)\end{array}$ & $\begin{array}{c}\text { LLDPE-g-MA } \\
(\text { wt \% })\end{array}$ & $\begin{array}{c}\text { Sample density } \\
\left(\text { g.cm }^{-3}\right)\end{array}$ \\
\hline LDPE/EVA_A or NA & 47.5 & 47.5 & 0 & 5.0 & 0.942 \\
LDPE/EVA/G5_A or NA & 45.1 & 45.1 & 5.0 & 4.7 & 0.951 \\
LDPE/EVA/G10_A or NA & 42.7 & 42.7 & 10.0 & 4.5 & 0.973 \\
LDPE/EVA/G15_A or NA & 40.3 & 40.3 & 15.0 & 4.2 & 0.991 \\
LDPE/EVA/G16_A or NA & 39.9 & 39.9 & 16.0 & 4.2 & 0.995 \\
LDPE/EVA/G17.5_A or NA & 39.1 & 39.1 & 17.5 & 4.1 & 0.998 \\
LDPE/EVA/G20_A or NA & 38.0 & 38.0 & 20.0 & 4.0 & 1.016 \\
\hline
\end{tabular}




\subsection{Characterizing and property measurement}

Graphene-like structure was observed using high-resolution transmission electron microscopy (HR-TEM JEOL $2170 \mathrm{~F}$ ) at a $200 \mathrm{kV}$ acceleration voltage. The morphology of the composite was investigated by a high-resolution scanning electron microscope (Hitachi SU-8230 FE-SEM). The test specimens were cryofractured by immersing in liquid nitrogen using a microtome and then the prepared cross-sections were coated with $\sim 2 \mathrm{~nm}$ platinum layer under vacuum condition using a turbo-pumped sputter coater/carbon coater $(\mathrm{Q} 150 \mathrm{~T})$.

The particle distribution size of the prepared graphene-like filler was evaluated by laser granulometry technique, using MASTERSIZER 3000 Malvern, by dispersing graphene-like filler in demineralized water at $3000 \mathrm{rpm}$ agitation speed and $90 \%$ sonication.

The conductivity of the clay graphene-like powder was measured using a laboratory setup. A sample holder was filled by $5 \mathrm{~g}$ clay graphene-like and the powder was subjected to several mechanical loads using universal testing machine. The conductivity of the powder was measured at different loads using a 4-cable ohmmeter.

The chemical interaction of LDPE polymer with EVA in presence of LLDPE-g-MA compatibilizer was assessed by performing Fourier transform infrared spectroscopy (FT-IR) test. FT-IR experiments were conducted in the absorbance mode over a wide range of wavelengths from (400-4000 s $\mathrm{s}^{-1}$ ) with Nicolet 6700 FT-IR Spectrometer.

Broadband dielectric spectroscopy was conducted using Novocontrol dielectric spectrometer to measure the electrical response of the polymer blend and composites over a wide range of frequencies and temperatures. A $0.5 \mathrm{~mm}$ thick sample disk with a diameter of $4 \mathrm{~cm}$ was mounted between two brass electrodes and subjected to an excitation voltage of $3 \mathrm{Vrms}$. The frequency domain electrical responses at different temperatures were obtained.

Differential scanning calorimetric (DSC) measurements were performed to analyze the change of melting point, as well as the crystallinity rate of composites. The experiment was conducted with a Perkin Elmar Pyris1 DSC apparatus at a heating ramp of $10{ }^{\circ} \mathrm{C} / \mathrm{min}$ from 20 to $150{ }^{\circ} \mathrm{C}$ under a $50 \mathrm{ml} / \mathrm{min}$ flow of argon, followed by a cooling step at the same rate to $20^{\circ} \mathrm{C}$, and consecutively, another heating step at $10{ }^{\circ} \mathrm{C} / \mathrm{min}$. Thermogravimetric analysis (TGA) was conducted using Diamond TG/DTA (Perkin Elmer technology via SII) with test specimens around $10 \mathrm{mg}$. The composite samples were heated under nitrogen atmosphere with a heating ramp of $20^{\circ} \mathrm{C} / \mathrm{min}$ from $100{ }^{\circ} \mathrm{C}$ to $600{ }^{\circ} \mathrm{C}$. 
To investigate the viscoelastic properties of the composite at molten state, rheological experiments were conducted at processing temperature of $155{ }^{\circ} \mathrm{C}$. Small Amplitude Oscillatory Shear (SAOS) test was conducted using Anton Paar MCR 501 in strain-controlled mode on test specimens of diameter of $25 \mathrm{~mm}$. A strain value of $0.03 \%$ with a range of frequency from of 0.01 to $300 \mathrm{rad} / \mathrm{s}$ was applied.

\section{Result and discussion}

\subsection{Graphene-like properties}

High-resolution transmission electron microscopy (HR-TEM) images of caramelized hybrid clay which was graphitized in inert atmosphere is shown in Figure 1. Graphene-like filler composed of bentonite layers, as well as multilayered graphene layers (white arrows in Figure 1) were seen. Caramelization of sucrose in bentonite and consequent graphitization led to greater layer spacing of graphene than the initial bentonite layers. The regional graphene layers, including several pilled-graphene layers can be seen clearly in graphene-rich region. The electrical conductivity of the graphene-like filler was measured and reported in our previous work [36]. The particle size distribution of the graphene-like is shown in supplementary materials. The significant portion of particles range in size from $800 \mathrm{~nm}$ to $10 \mu \mathrm{m}$. The electrical conductivity of the prepared graphene-like powder increased with mechanical loading (Figure 2), which indicates that the graphene-like materials can behave as a pressure sensor. At low loads, due to the low contacts between the particles and the existence of the air within the structure, the measured conductivity was low. However, at higher loads a greater conductivity (between 100 to $165 \mathrm{~S} / \mathrm{m}$ ) was obtained, potentially due to the formation of the conductive pathways and higher number of particle-particle contacts [1]. The dependency of the electrical conductivity of graphene-like powders to an external load has created significant paradigm for sensor and switching applications which has been frequently addressed [48, 49]. 


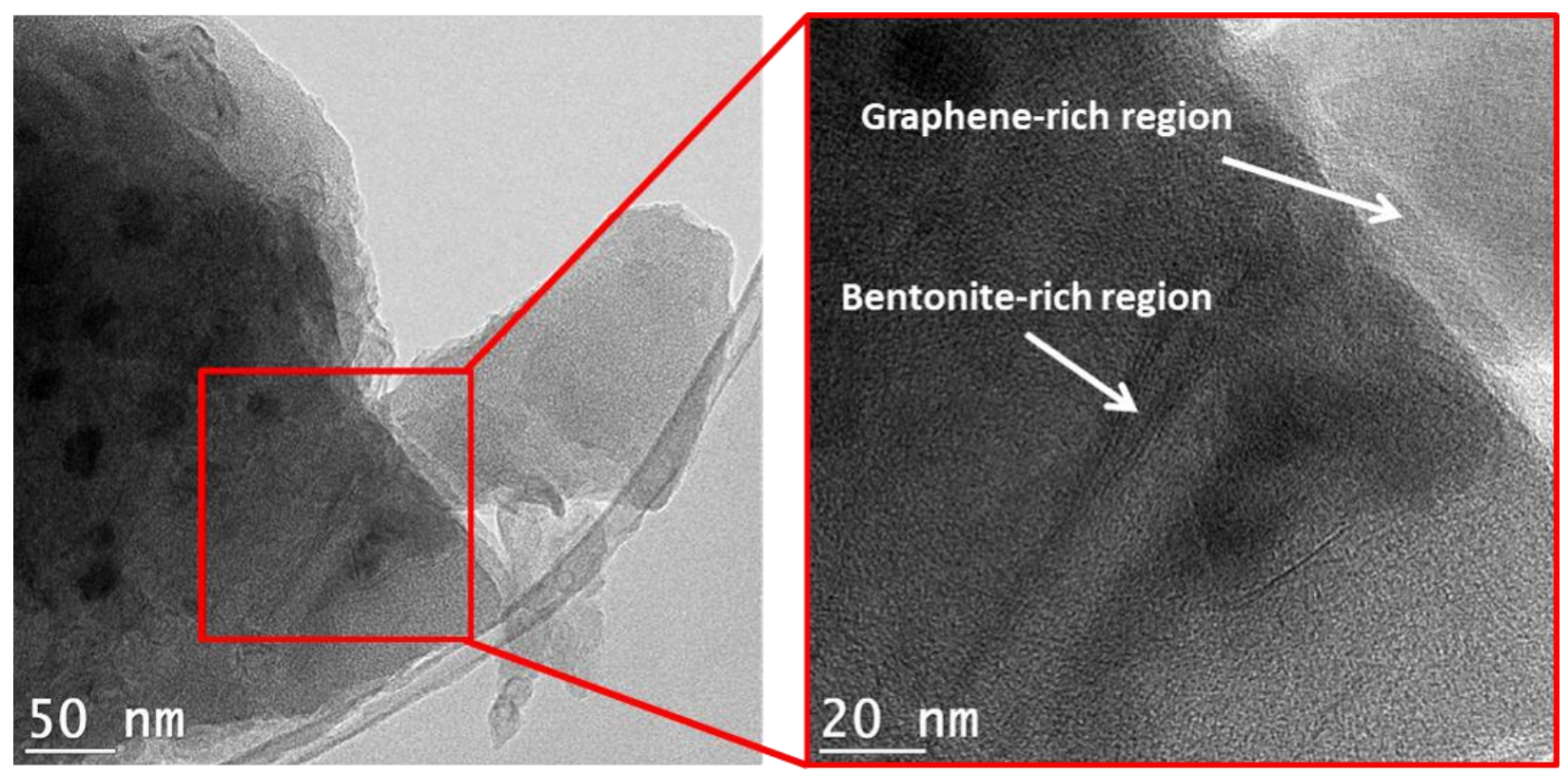

Figure 1: High-resolution transmission electron microscopy (HR-TEM) images of graphene-like layers.

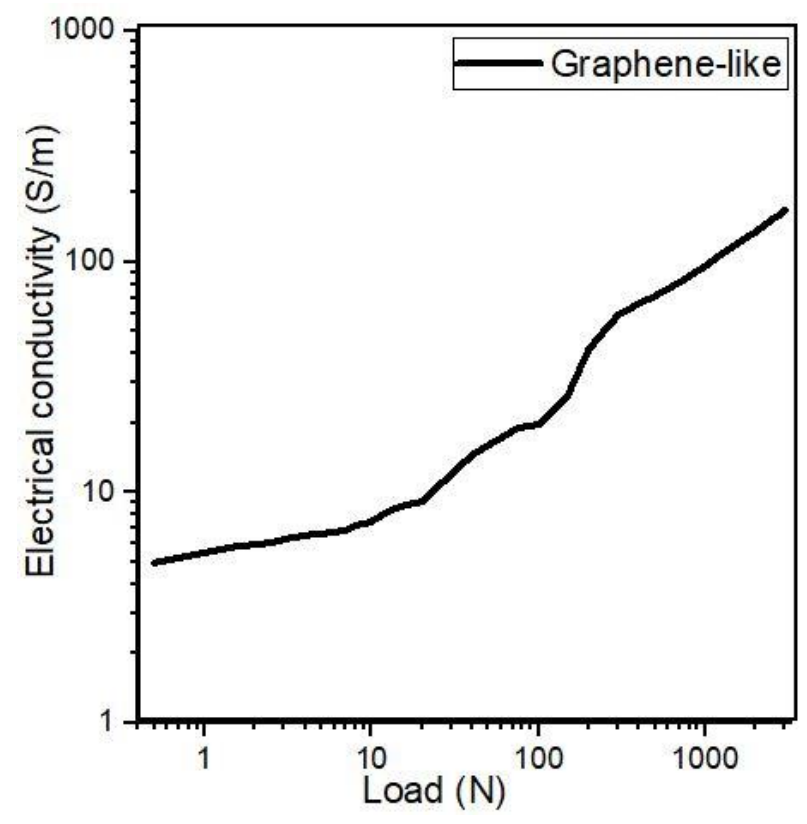

Figure 2: Electrical conductivity of the clay graphene-like powder as a function of applied load.

\subsection{Scanning electron microscopy (SEM) images}

The morphology of the blend LDPE/EVA_A blend was observed to change with the graphene-like filler concentration (Figure 3). The SEM micrograph at 2K magnification of LDPE/EVA/G15_A, which 
contained $15 \mathrm{wt} \%$ filler, (Figure 3c) shows agglomerated graphene-like flakes which are nearly stacked together and form islands of particles, distributed within the composite compared to the LDPE/EVA/G20_A at the same magnification (Figure 3e), which contained $20 \mathrm{wt} \%$ filler. At the higher filler content, the number of contacts between graphene-like particles was increased and a network was formed throughout the composite that can be clearly seen in Figure 3e. The SEM image of the LDPE/EVA/G20_A with higher magnification shows a suitable dispersion as well as distribution of graphene-like particles layered within the composite with the particle size of up to $2 \mu \mathrm{m}$. 

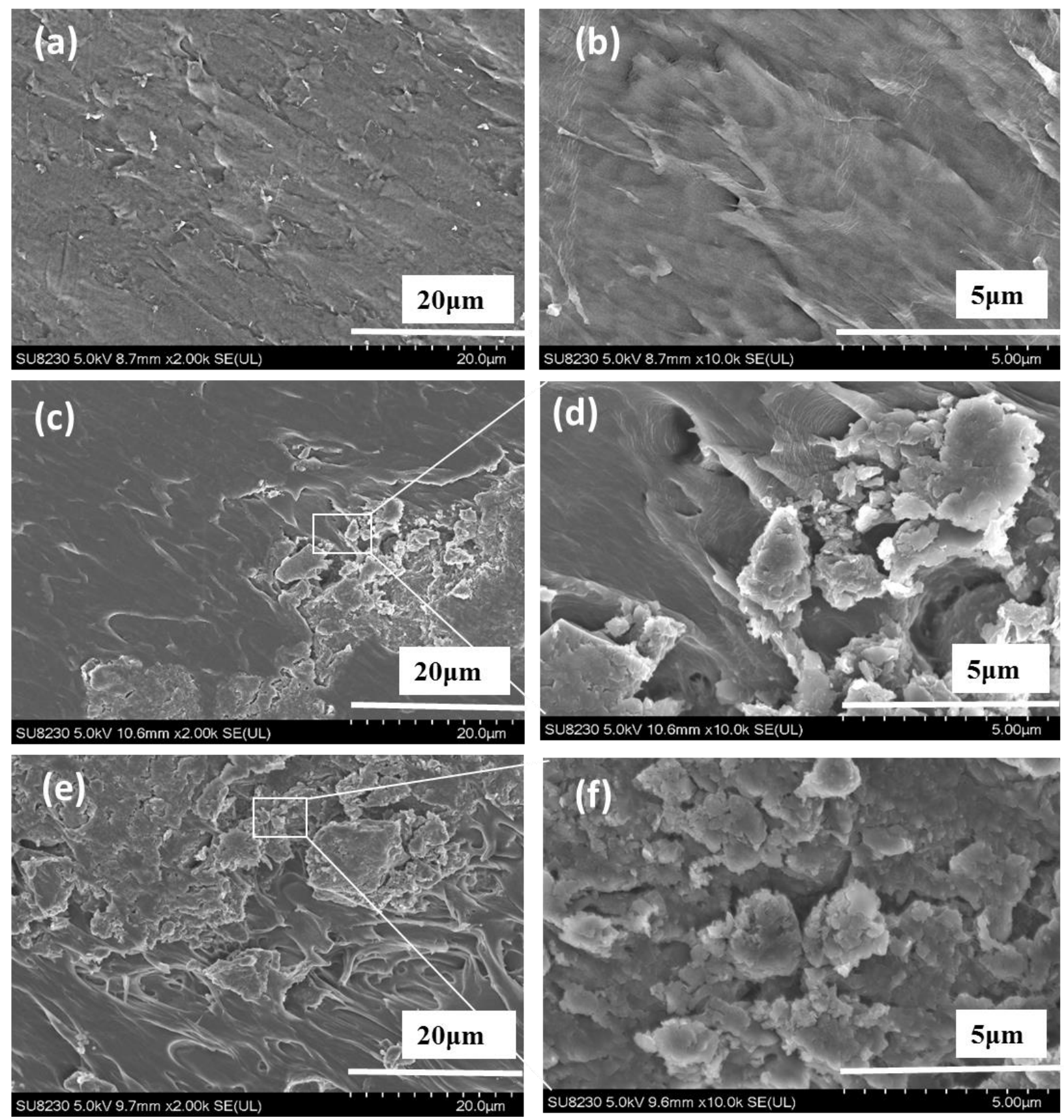

Figure 3: SEM micrographs of (a, b) LDPE/EVA_A blend, (c, d) LDPE/EVA/G15_A and (e, f) LDPE/EVA/G 20_A.

\subsection{FT-IR results}

Figure 4 represents the FT-IR spectra of the neat LDPE, neat EVA, LDPE/EVA_A blend, and LDPE/EVA/G_A composites compounded with LLDPE-g-MA as a compatibilizer. FT-IR spectra represent information about the chemical structure of components, as well as the conformation and 
configuration. The FT-IR spectra indicate that there is no significant chemical interaction between the polymer blend and graphene. The FTIR spectra of the graphene containing composites showed the same absorption bands than the neat polymers (LDPE and EVA). EVA spectrum exhibited two sharp peaks at $1720-1745 \mathrm{~cm}^{-1}$ and $1100-1200 \mathrm{~cm}^{-1}$, which are attributed to the stretching vibration of $\mathrm{C}=\mathrm{O}$ and $\mathrm{C}-\mathrm{O}$ bonds, respectively [3, 50, 51]. The FT-IR spectra revealed two intensive peaks at 2850 and $2910 \mathrm{~cm}^{-1}$ for all samples, which are assigned to the ethylene groups existing in both the LDPE and EVA components. The intensity of both the peaks (2850 and $2910 \mathrm{~cm}^{-1}$ ) decreased with an increase of graphene-like content and the decrease of ethylene groups. The lower intensity confirms the bulk value of the graphene-like filler in the membrane of the polymer has increased $[50,52,53]$. 


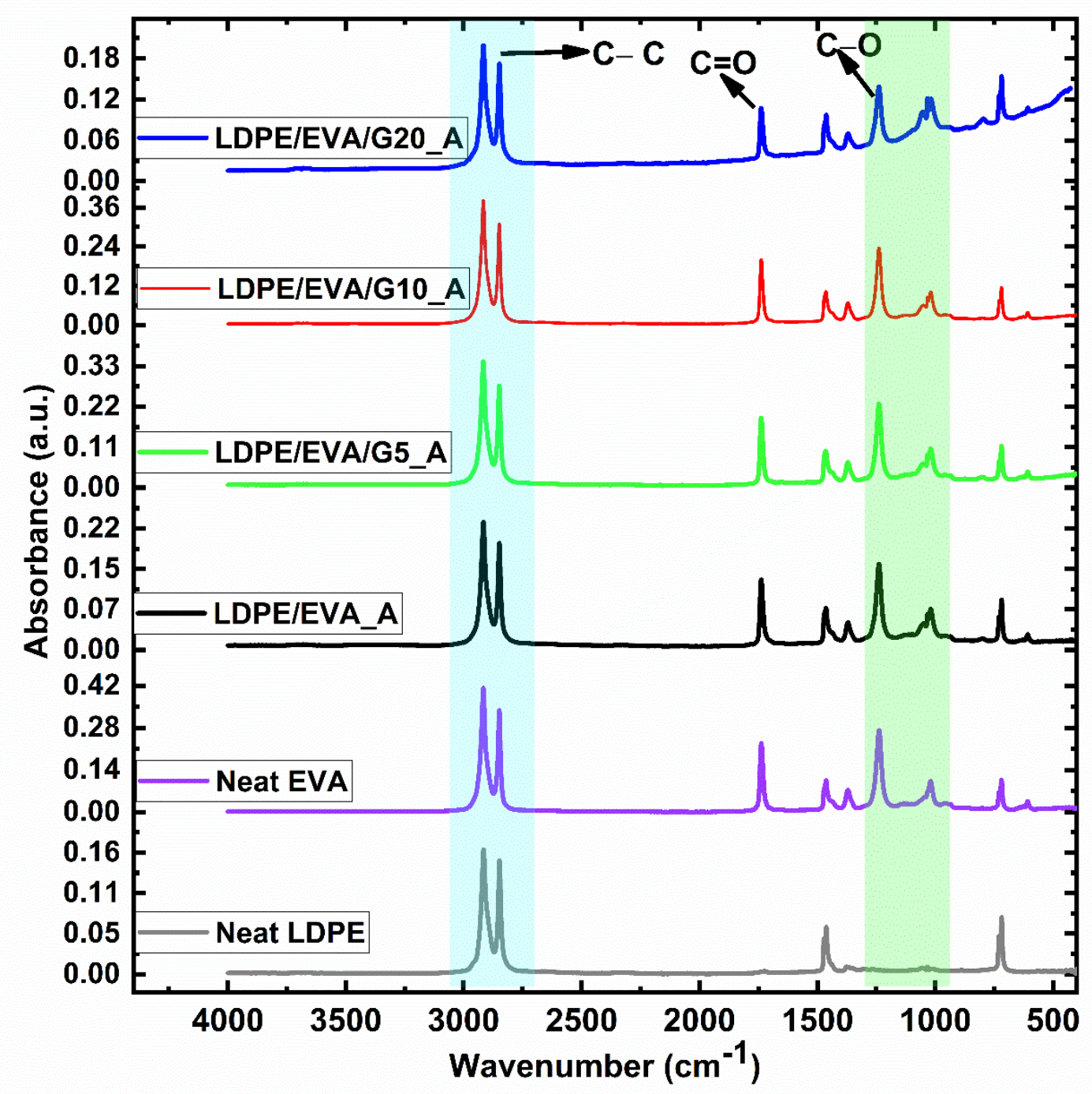

Figure 4: FT-IR spectra of the LDPE, EVA, LDPE/EVA_A blend and LDPE/EVA/G_A composites over the range of wavelengths of 400 to $4000 \mathrm{~s}^{-1}$.

\subsection{Electrical characterization}

The dielectric responses of the LDPE/EVA/G composites at room temperature prepared via annealed and non-annealed techniques are shown in Figure 5 and Figure 6, respectively. The complex permittivity of a material is expressed by Equation 1, where $\varepsilon$ ' represents storage part and $\varepsilon^{\prime \prime}$ denotes the loss part,

$$
\varepsilon^{*}(\omega)=\varepsilon^{\prime}(\omega)-\mathrm{j} \varepsilon^{\prime \prime}(\omega)
$$


For a pure Debye relaxation process, the complex permittivity (real and imaginary part) is given:

$$
\begin{aligned}
& \varepsilon^{\prime}=\varepsilon_{\infty}+\frac{\varepsilon_{\mathrm{s}}-\varepsilon_{\infty}}{1+\omega^{2} \tau^{2}} \\
& \varepsilon^{\prime \prime}=\frac{\left(\varepsilon_{\mathrm{s}}-\varepsilon_{\infty}\right) \omega \tau}{1+\omega^{2} \tau^{2}}
\end{aligned}
$$

where $\tau$ is the time constant of the process. As illustrated, the addition of graphene-like filler to LDPE/EVA blend did not significantly increase the real part of the permittivity (the dielectric constant) of annealed and non-annealed composites at low filler contents. However, a tremendous change in electrical conductivity of the composites was found for both annealed and non-annealed composites with addition of $17.5 \mathrm{wt} \%$ of graphene-like filler which corresponds to the electrical percolation threshold for both systems [54]. A parallel trend was observed in LDPE/EVA/metallic oxide composites in their thermal and mechanical properties [2]. The annealed composites were found to be slightly more conductive (one order of magnitude) than the non-annealed counterparts near the percolation threshold due to better graphene layered arrangement within the polymer chains as explained by Kurusu et al. [47] (Figure 7).
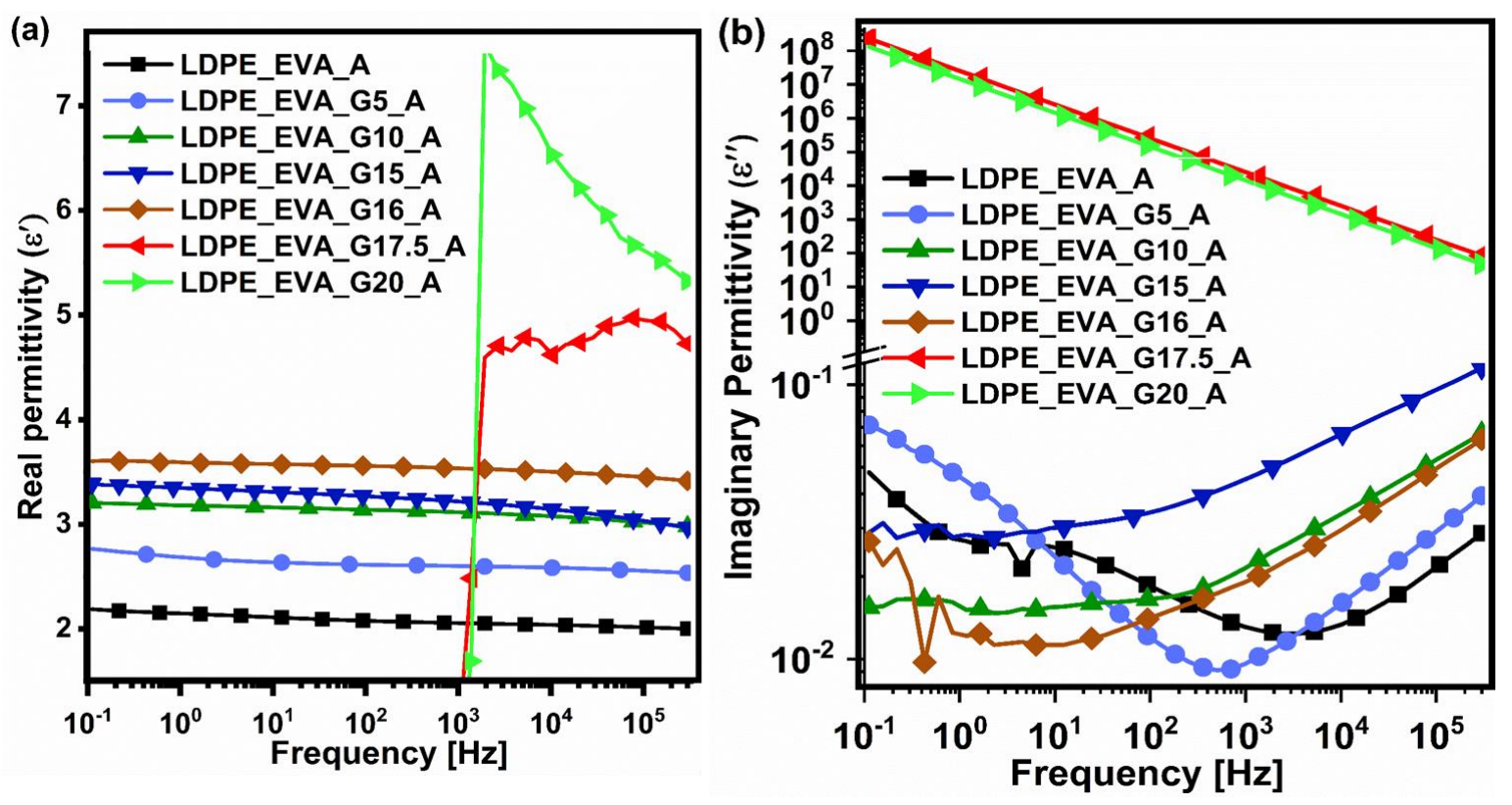

Figure 5: Real and imaginary part of the LDPE/EVA/G_A composites at room temperature. 

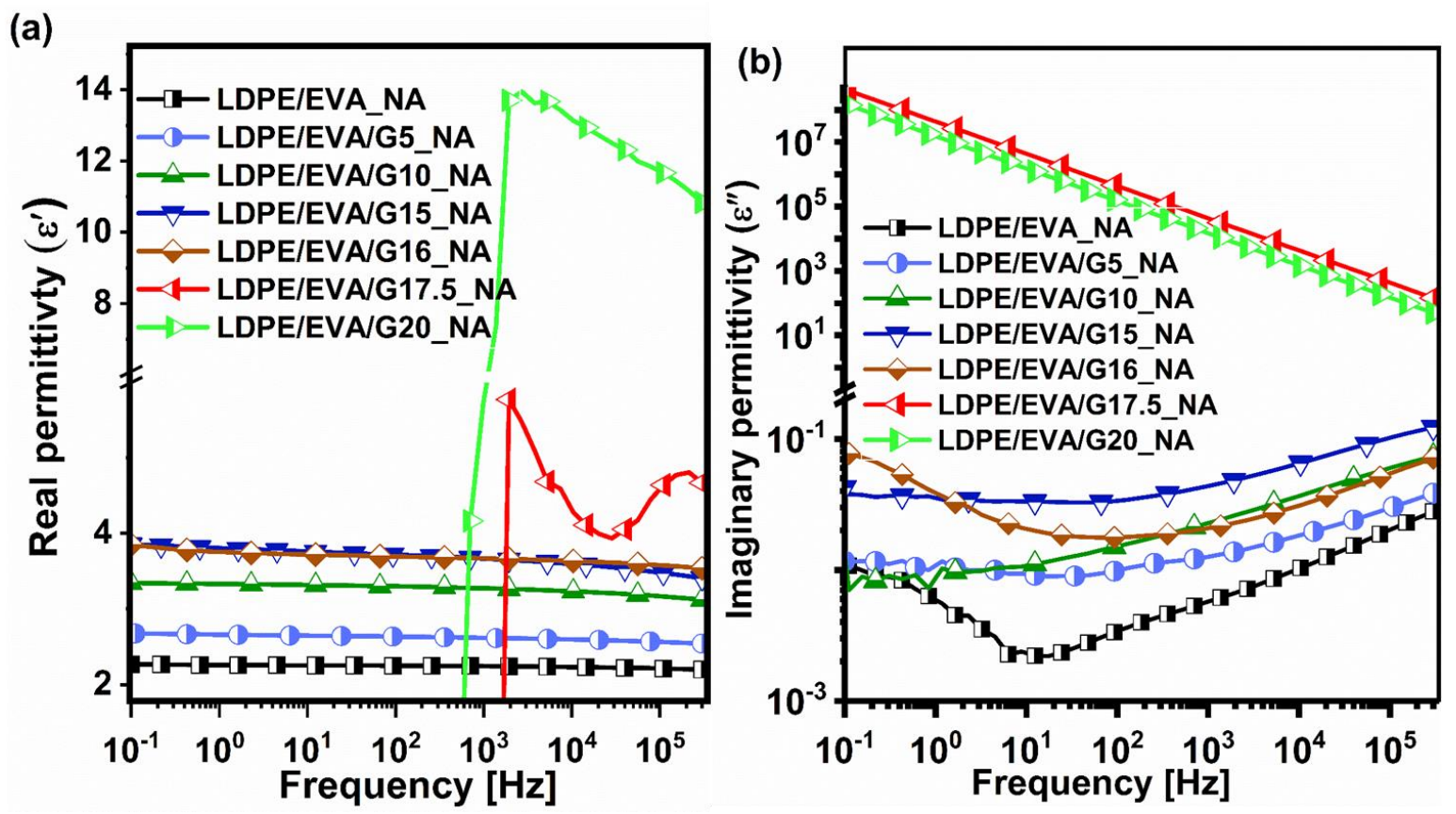

Figure 6: Real and imaginary part of the LDPE/EVA/G_NA composites at room temperature

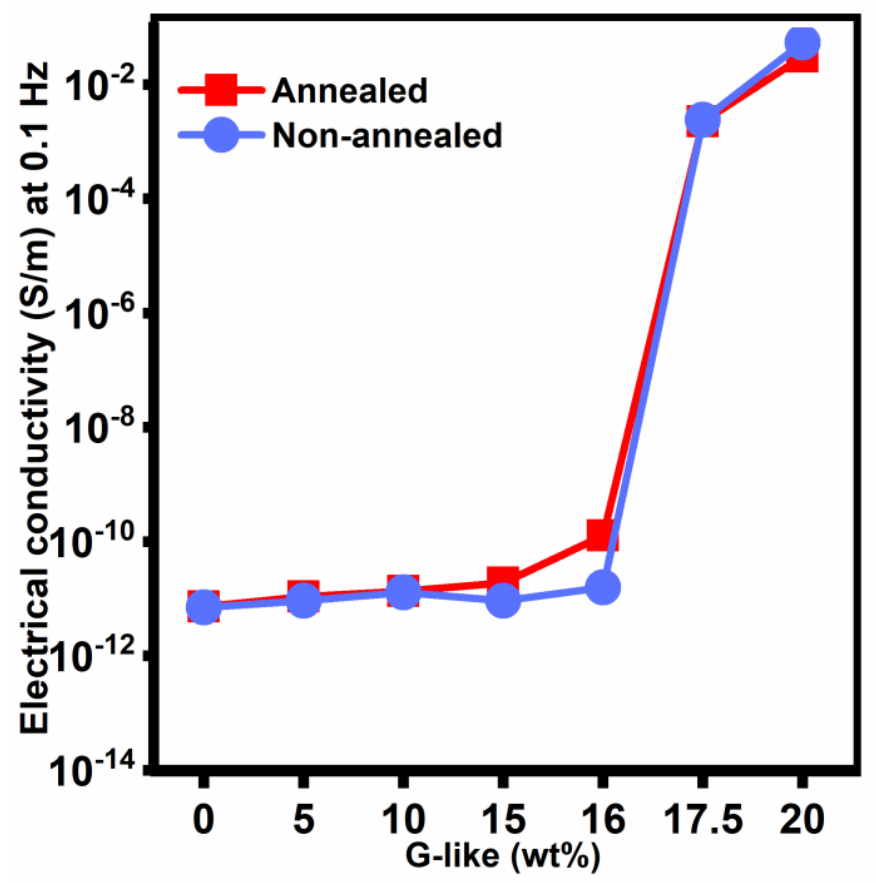

Figure 7: Electrical conductivity of LDPE/EVA/G composites at different filler contents prepared via annealing and non-annealing methods. 
Figure 8 shows the loss part of the electrical response of the LDPE/EVA/G composite for frequency range of $100 \mathrm{mHz}$ to $100 \mathrm{kHz}$ at different temperatures starting from room temperature to $85{ }^{\circ} \mathrm{C}$. For the subpercolating systems, Figs $8 \mathrm{a}$ to $8 \mathrm{e}$, a clear increase to the imaginary part at higher temperatures and low frequencies (the corner in the back of the figure) was systematically observed due to charge transport processes leading to a mixture of direct conductivity and electrode polarization processes. In addition, the dielectric relaxation peaks in polymer blends appear broader than those of the neat polymers. As can be seen in Figure $8 \mathrm{f}$ and g, LDPE/EVA/G17.5 and LDPE/EVA/G20 annealed composites have become semiconductive and the transition from the insulating to the conductive regime was found to occur at a filler content between 16 to $17.5 \mathrm{wt} \%$. 

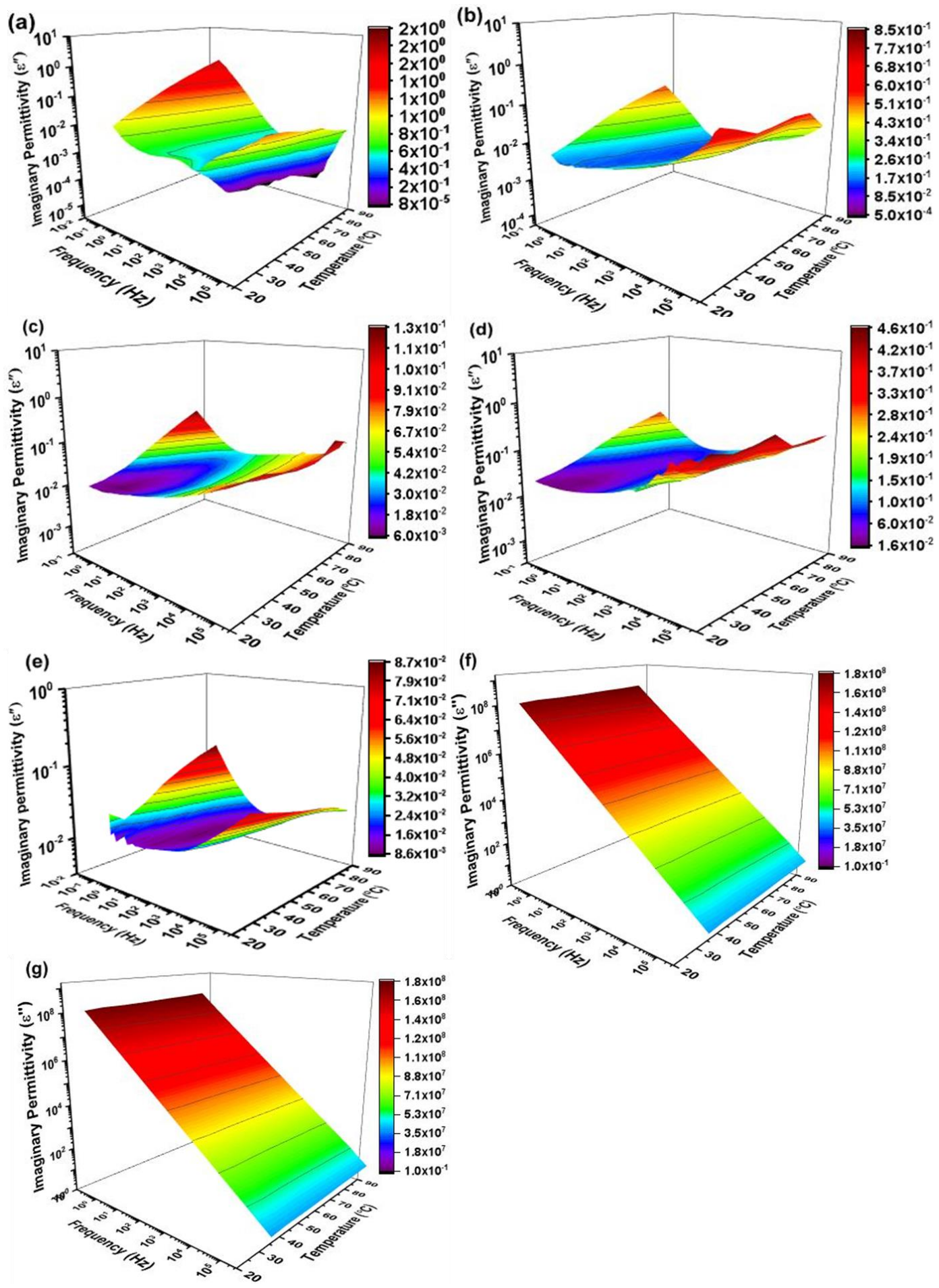

Figure 8: Imaginary part of electric response of LDPE/EVA/G composite at different temperatures over the wide range of frequency, (a) LDPE/EVA_A blend, (b) LDPE/EVA/G5_A, (c) LDPE/EVA/G10_A, (d) LDPE/EVA/G15_A, (e) LDPE/EVA/G16_A (f) LDPE/EVA/G17.5_A and (g) LDPE/EVA/G20_A. 


\subsection{Thermal characterizations (DSC and TGA)}

The DSC thermograms of LDPE/EVA/G composites are shown in Figures 9a,c (melting endotherms) and 9b,d (crystallization endotherms). The heating thermograms showed a wide peak, starting from $40{ }^{\circ} \mathrm{C}$ to 95 ${ }^{\circ} \mathrm{C}$ which is attributed to the melting of EVA crystals. This overlapped with the second peak which was found to lay between $105{ }^{\circ} \mathrm{C}$ to $117^{\circ} \mathrm{C}$. The second peak originating from the melting of PE crystals was found to be of larger intensity than the previous due to the greater crystallinity of LDPE than EVA [55]. The absorbed energy (enthalpy of fusion) of the composites was found to be greater than the polymer blends due to the nucleation effect of the graphene-like filler [56-60]. The cooling thermographs showed a modest peak around $70{ }^{\circ} \mathrm{C}$ which is linked to the vinyl acetate crystal formation and another peak at $95{ }^{\circ} \mathrm{C}$ which is related to PE crystal formation [61]. The addition of graphene-like filler did not shift neither the melting point nor the crystallization temperature for all the annealed and non-annealed composites. 

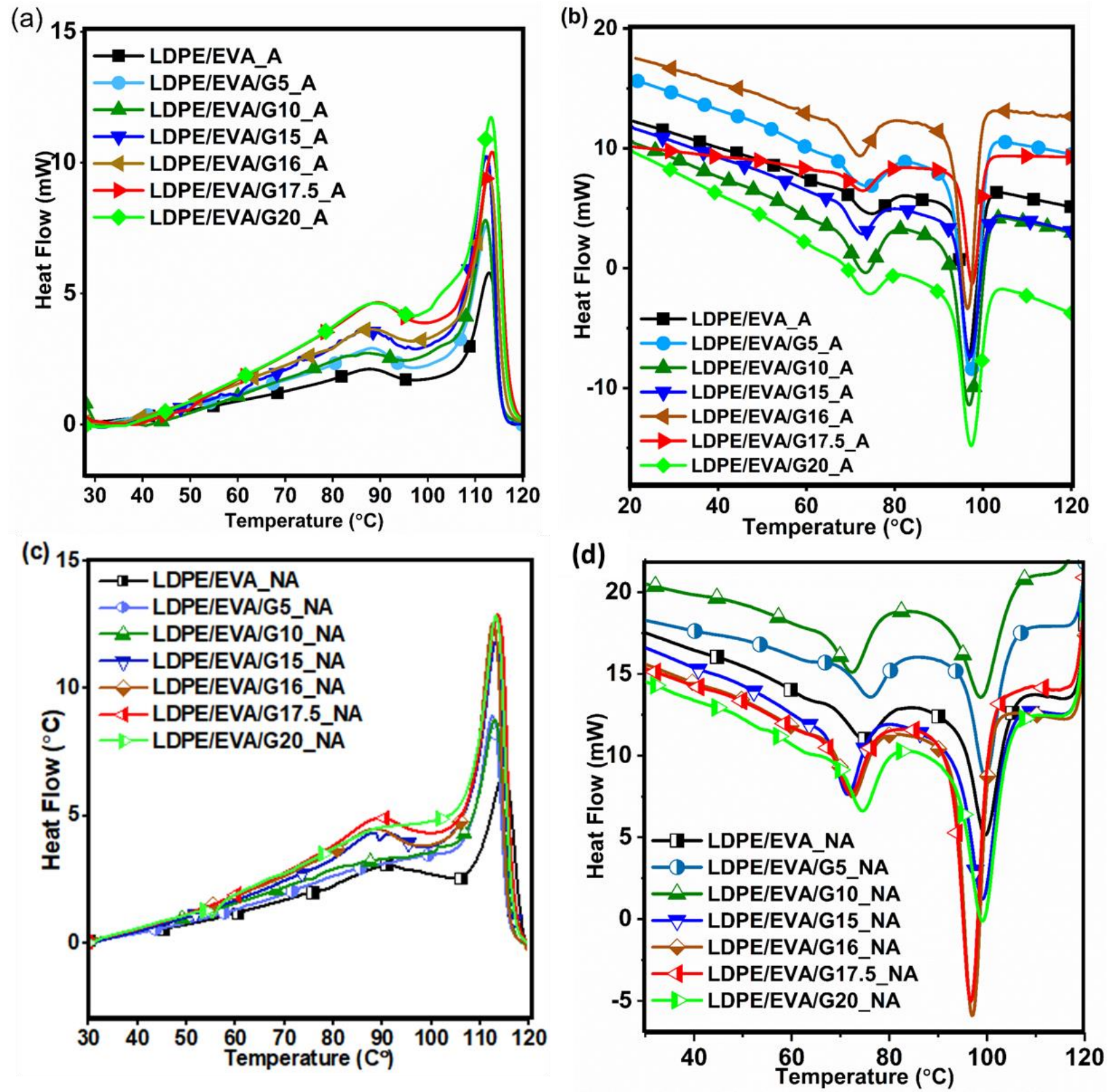

Figure 9: DSC thermograms, $(a, c)$ heating curves and $(b, d)$ cooling curves of the LDPE/EVA_A and LDPE/EVA_A polymer blend and corresponding composites at different temperatures.

The thermal stability of the composites and the true filler content were investigated by the means of TGA. Figure 10 shows the TGA thermograms of LDPE/EVA composites with graphene-like filler in the range of temperature from 100 to $600{ }^{\circ} \mathrm{C}$. Two decomposition zones were clearly visible in which the first weight loss starting from $300{ }^{\circ} \mathrm{C}$, and is related to division of vinyl acetate chains (deacylation) [2]. The second weight loss occurred at 370,430 and $450{ }^{\circ} \mathrm{C}$ can be attributed to the pyrolysis of the LDPE/EVA_A, LDPE/EVA/G10_A, and LDPE/EVA/G20_A polymer chains [62]. An increase of $80{ }^{\circ} \mathrm{C}$ was seen in the 
second weight loss of the composite containing $20 \mathrm{wt} \%$ graphene-like due to the filler network formed throughout the composite which is acting similar to a cross-linked matrix [63-67]. A minor weight loss at higher temperatures (above $550{ }^{\circ} \mathrm{C}$ ) is observed which is assigned to the existing oxygenated groups within the graphene-like filler [68]. The remained ash at $520{ }^{\circ} \mathrm{C}$ (listed in Table 2) for the composites confirmed the accuracy of the filler content in the synthesized samples.

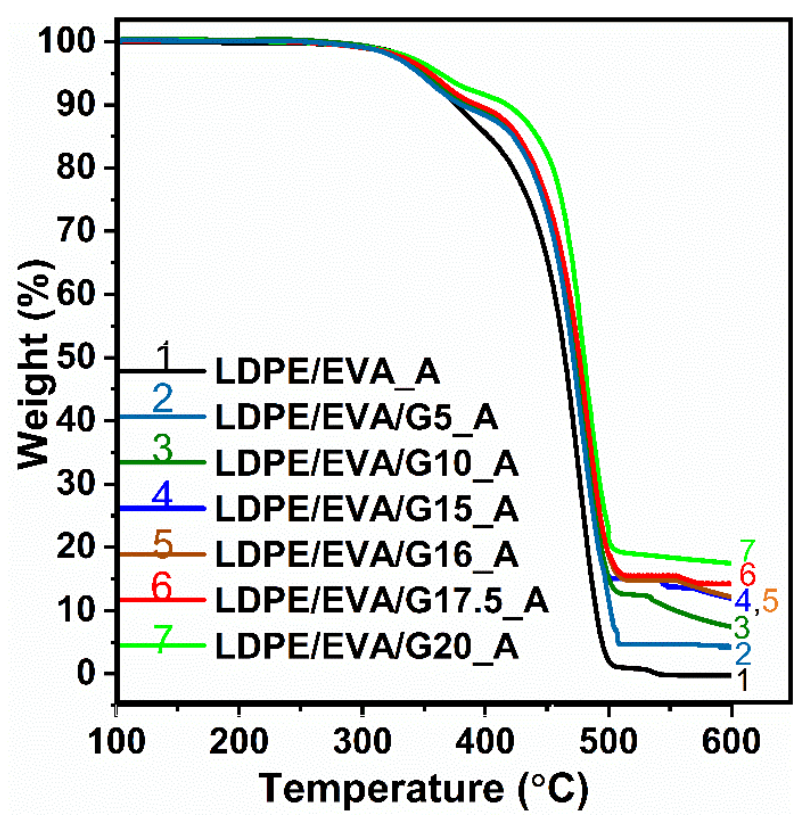

Figure 10: TGA thermograms of LDPE/EVA_A blend, LDPE/EVA/G10_A and LDPE/EVA/G20_A.

Table 2: TGA results of LDPE/EVA blend and its composites with graphene-like.

\begin{tabular}{lccc}
\hline Sample & T at 5 \% wt loss & T at 50\% wt loss & Ash content (\%) at 520 \\
\hline LDPE/EVA_A & 370 & 460 & 1.2 \\
LDPE/EVA/G5_A & 375 & 465 & 4.8 \\
LDPE/EVA/G10_A & 430 & 471 & 10.4 \\
LDPE/EVA/G15_A & 433 & 473 & 14.8 \\
LDPE/EVA/G16_A & 438 & 473 & 15.1 \\
LDPE/EVA/G17.5_A & 441 & 486 & 17.3 \\
LDPE/EVA/G20_A & 450 & 489 & 19.1 \\
\hline
\end{tabular}

\subsection{Rheological properties}

To understand the structure of LDPE/EVA blend and its composites in the molten state, rheology experiments were performed in the small amplitude oscillatory shear (SAOS) mode as a function of angular frequency $(\omega)$. The rheological results are shown in Figure 11a (storage modulus, G') and 11b (complex viscosity modulus, $\left.\eta^{*}\right)$. The linear viscoelastic response of polymeric composites at filler content below the 
percolation threshold depicts a terminal behavior at low frequency in which the storage modulus $\left(\mathrm{G}^{\prime}\right)$ is proportional to $\omega^{2}$ [69]. Below percolation, the storage modulus was not found to increase significantly. As the content of filler increases, the slope of the storage modulus versus the angular frequency decreases, especially above the percolation threshold [70, 71]. At $20 \mathrm{wt} \%$ (LDPE/EVA/G20_A) a transition occurred and the material showed a pseudo-solid-like curve, which is related to the formation of strong particles networks throughout the composite, leading to a noticeable increase of storage modulus, as found in [72]. This also leads to a remarkable increase of complex viscosity of the molten composite [61, 73]. These changes in the structure of the composite at molten state are in a good agreement with the electrical properties, as well as the SEM micrographs, corroborating, formation of electric network, higher thermal stability and connected particles network. 

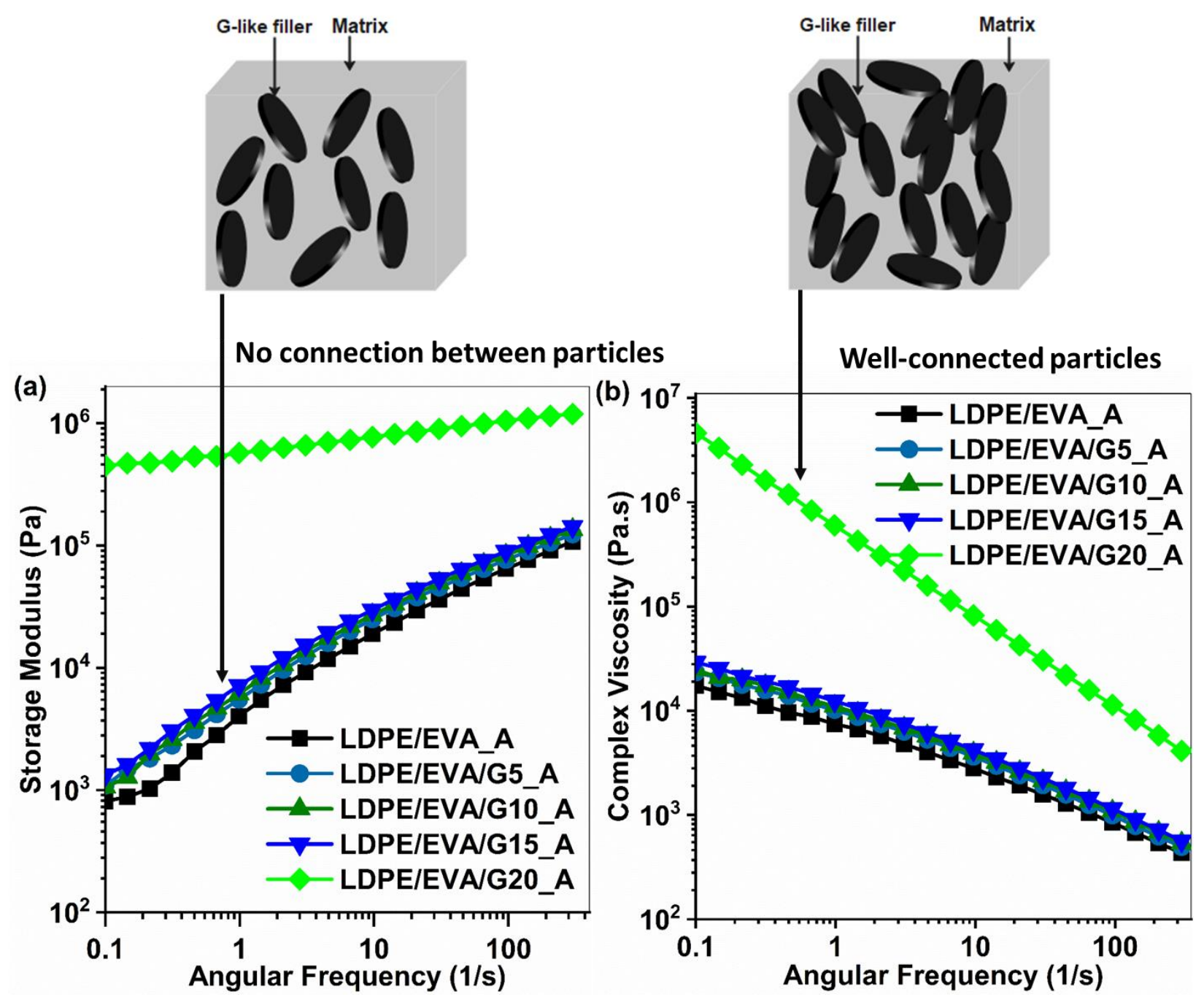

Figure 11: Small amplitude oscillatory shear measurements of LDPE/EVA_A polymer blend and its composites with graphene-like: (a) storage modulus $\left(\mathrm{G}^{\prime}\right)$ and $(\mathrm{b})$ complex viscosity modulus $\left(\eta^{*}\right)$ as a function of angular frequency.

\section{Conclusions}

In this study, a novel application of semi-conductive graphene-like filler was used to improve the electrical conductivity of a polymer blend composite. Low-density polyethylene (LDPE), a non-polar thermoplastic polymer, and ethylene vinyl acetate (EVA), an elastomer polymer, were selected to form the polymeric matrix due to their wide reaching commercial use. A conductive microstructural network was achieved for the LDPE/EVA/G composite with addition of more than 16 wt \% of the graphene-like filler. Indeed, the electrical conductivity of the polymer blend was found to increase from $10^{-14}$ to $10^{-6} \mathrm{~S} / \mathrm{cm}$ at $17.5 \mathrm{wt} \%$ of graphene-like, which makes this composite a suitable candidate for semi-conductive and antistatic 
applications. Annealing of the composites further increased the electrical conductivity near the percolation threshold. Furthermore, the thermal stability of the composite was increased by $80{ }^{\circ} \mathrm{C}$ with the addition of $20 \mathrm{wt} \%$ graphene-like filler. Graphene-like materials, as studied in this work as a filler, offer a new avenue to tailor the electrical properties of the polymers for conductive or semi-conductive applications while avoiding high filler contents required when using conventional graphene filler technologies. Surface modifications of the graphene-like composite, refinement of mixing protocols and exploration of other polymer matrices are potential areas of improvement to continue to reduce the required filler loading and to maximize the property improvements.

\section{Acknowledgment}

The authors thank Natural Sciences and Engineering Research Council of Canada for the support.

\section{References}

[1] Jia LC, Yan DX, Cui CH, Ji X, Li ZM. A unique double percolated polymer composite for highly efficient electromagnetic interference shielding. Macromolecular Materials and Engineering. 2016;301(10):1232-41.

[2] Haurie L, Fernández AI, Velasco JI, Chimenos JM, Cuesta J-ML, Espiell F. Thermal stability and flame retardancy of LDPE/EVA blends filled with synthetic hydromagnesite/aluminium hydroxide/montmorillonite and magnesium hydroxide/aluminium hydroxide/montmorillonite mixtures. Polym Degrad Stab. 2007;92(6):1082-7.

[3] Zarandi MB, Bioki HA. Thermal and mechanical properties of blends of LDPE and EVA crosslinked by electron beam radiation. The European Physical Journal-Applied Physics. 2013;63(2).

[4] Xiaoming LJXXT, Shuangnan YWZ. Effect of CPE on PTC Conductive PE/EVA/CB Composite [J]. China Plastics Industry. 2001;4:012.

[5] Silva C, Caridade SG, Cunha E, Sousa MP, Rocha H, Mano JF, et al. Nanostructured Biopolymer/FewLayer Graphene Freestanding Films with Enhanced Mechanical and Electrical Properties. Macromolecular Materials and Engineering. 2018;303(4):1700316.

[6] Utracki LA, Wilkie CA. Polymer blends handbook: Springer; 2002.

[7] Utracki LA. Clay-containing polymeric nanocomposites and their properties. IEEE Electrical Insulation Magazine. 2010;26(4).

[8] Sadasivuni KK, Ponnamma D, Kim J, Thomas S. Graphene-based polymer nanocomposites in electronics: Springer; 2015.

[9] Huang Y, Jiang S, Wu L, Hua Y. Characterization of LLDPE/nano-SiO 2 composites by solid-state dynamic mechanical spectroscopy. Polym Test. 2004;23(1):9-15.

[10] Azizi S, Ouellet-Plamondon C, David E, Fréchette M. Electrical and thermal properties of low-density polyethylene/graphene-like composite. Electrical Insulation and Dielectric Phenomenon (CEIDP), 2017 IEEE Conference on: IEEE; 2017. p. 517-20.

[11] Raju GG. Dielectrics in electric fields: CRC press; 2016.

[12] Bellucci F, Fabiani D, Montanari G, Testa L. The processing of nanocomposites. Dielectric Polymer Nanocomposites: Springer; 2010. p. 31-64.

[13] Kremer F, Huwe A, Schönhals A, Rózanski S. 6 Molecular Dynamics in Confining Space: Springer; 2012.

[14] Tjong SC, Mai Y-W. Physical properties and applications of polymer nanocomposites: Elsevier; 2010. 
[15] Helal E, Pottier C, David E, Fréchette M, Demarquette N. Polyethylene/Thermoplastic elastomer/Zinc Oxide nanocomposites for high voltage insulation applications: Dielectric, mechanical and rheological behavior. Eur Polym J. 2018.

[16] Azizi S, David E, Fréchette MF, Nguyen-Tri P, Ouellet-Plamondon CM. Electrical and thermal phenomena in low-density polyethylene/carbon black composites near the percolation threshold. J Appl Polym Sci. 2018:47043.

[17] Khanam PN, AlMaadeed M, Ouederni M, Harkin-Jones E, Mayoral B, Hamilton A, et al. Melt processing and properties of linear low density polyethylene-graphene nanoplatelet composites. Vacuum. 2016;130:63-71.

[18] Bakar NA, Chee CY, Abdullah LC, Ratnam CT, Ibrahim NA. Thermal and dynamic mechanical properties of grafted kenaf filled poly (vinyl chloride)/ethylene vinyl acetate composites. Materials \& Design (1980-2015). 2015;65:204-11.

[19] Sonnier R, Viretto A, Dumazert L, Longerey M, Buonomo S, Gallard B, et al. Fire retardant benefits of combining aluminum hydroxide and silica in ethylene-vinyl acetate copolymer (EVA). Polym Degrad Stab. 2016;128:228-36.

[20] Zhang Y, Wang B, Sheng H, Yuan B, Yu B, Tang G, et al. Enhanced fire-retardancy of poly (ethylene vinyl acetate) electrical cable coatings containing microencapsulated ammonium polyphosphate as intumescent flame retardant. RSC Advances. 2016;6(88):85564-73.

[21] Calegari F, de Souza LP, Barsan MM, Brett CM, Marcolino-Junior LH, Bergamini MF. Construction and evaluation of carbon black and poly (ethylene co-vinyl) acetate (EVA) composite electrodes for development of electrochemical (bio) sensors. Sensors and Actuators B: Chemical. 2017;253:10-8.

[22] Henderson AM. Ethylene-vinyl acetate (EVA) copolymers: a general review. IEEE Electrical Insulation Magazine. 1993;9(1):30-8.

[23] Huang JC, Wu CL. Processability, mechanical properties, and electrical conductivities of carbon blackfilled ethylene-vinyl acetate copolymers. Adv Polym Tech. 2000;19(2):132-9.

[24] Zhang Y, Tan Y-W, Stormer HL, Kim P. Experimental observation of the quantum Hall effect and Berry's phase in graphene. nature. 2005;438(7065):201.

[25] Kim H, Abdala AA, Macosko CW. Graphene/polymer nanocomposites. Macromolecules. 2010;43(16):6515-30.

[26] Kuilla T, Bhadra S, Yao D, Kim NH, Bose S, Lee JH. Recent advances in graphene based polymer composites. Prog Polym Sci. 2010;35(11):1350-75.

[27] Qian S, Liu H, de Rooji MR, Schlangen E, Guard WF, van de Kuilen Jw. Self-healing composites for sustainable infrastructures. SASBE2009.

[28] Zhao H, Ding J, Yu H. Variation of mechanical and thermal properties in sustainable graphene oxide/epoxy composites. Scientific reports. 2018;8(1):16560.

[29] Mohan VB, Lau K-t, Hui D, Bhattacharyya DJCPBE. Graphene-based materials and their composites: a review on production, applications and product limitations. 2018;142:200-20.

[30] Azizi S, David E, Fréchette MF, Nguyen-Tri P, Ouellet-Plamondon C. Electrical and thermal conductivity of ethylene vinyl acetate composite with graphene and carbon black filler. Polym Test. 2018.

[31] Stankovich S, Dikin DA, Dommett GH, Kohlhaas KM, Zimney EJ, Stach EA, et al. Graphene-based composite materials. nature. 2006;442(7100):282.

[32] Wang Q, Meng Q, Wang T, Guo W. High-performance antistatic ethylene-vinyl acetate copolymer/high-density polyethylene composites with graphene nanoplatelets coated by polyaniline. J Appl Polym Sci. 2017;134(37).

[33] Ruiz-Hitzky E, Sobral MMC, Gómez-Avilés A, Nunes C, Ruiz-García C, Ferreira P, et al. ClayGraphene Nanoplatelets Functional Conducting Composites. Advanced Functional Materials. 2016.

[34] Qiu H-J, Guan Y, Luo P, Wang Y. Recent advance in fabricating monolithic 3D porous graphene and their applications in biosensing and biofuel cells. Biosens Bioelectron. 2017;89:85-95.

[35] Wang S, Wu Z-S, Zheng S, Zhou F, Sun C, Cheng H-M, et al. Scalable fabrication of photochemically reduced graphene-based monolithic micro-supercapacitors with superior energy and power densities. ACS nano. 2017;11(4):4283-91. 
[36] Boussaboun Z, Azizi S, Ouellet-Plamondon C. Conductive clay containing graphene layers. Nanotechnology (IEEE-NANO), 2017 IEEE 17th International Conference on: IEEE; 2017. p. 1065-9.

[37] Azizi S, David E, Fréchette MF, Nguyen-Tri P, Ouellet-Plamondon CM. Electrical and thermal conductivity of ethylene vinyl acetate composite with graphene and carbon black filler. Polymer Testing. 2018;72:24-31.

[38] Ruiz-Hitzky E, Sobral MMC, Gómez-Avilés A, Nunes C, Ruiz-García C, Ferreira P, et al. ClayGraphene Nanoplatelets Functional Conducting Composites. Advanced Functional Materials. 2016;26(41):7394-405.

[39] Ruiz-Garcia C, Darder M, Aranda P, Ruiz-Hitzky E. Toward a green way for the chemical production of supported graphenes using porous solids. Journal of Materials Chemistry A. 2014;2(7):2009-17.

[40] Anh TT, Fréchette M, David É, Ouellet-Plamondon C. Impact of nature and preparation method of graphene on the electrical behavior of LDPE/Graphene composites. Electrical Insulation and Dielectric Phenomena (CEIDP), 2016 IEEE Conference on: IEEE; 2016. p. 659-62.

[41] Pirondelli A, Fabiani D, Fréchette M, Bouanga CV, Guo M, David È. Electric and thermal properties of polyethylene-based nanodielectrics containing graphene-like additives. Electrical Insulation and Dielectric Phenomena (CEIDP), 2016 IEEE Conference on: IEEE; 2016. p. 615-8.

[42] Mancinelli P, Santangelo V, Fabiani D, Saccani A, Toselli M, Frechette M. LDPE composite materials obtained from building blocks containing standardized graphene interfaces. Electrical Insulating Materials (ISEIM), Proceedings of 2014 International Symposium on: IEEE; 2014. p. 421-4.

[43] Yuan N, Ma F, Fan Y, Liu Y, Ding J. High conductive ethylene vinyl acetate composites filled with reduced graphene oxide and polyaniline. Composites Part A: Applied Science and Manufacturing. 2012;43(12):2183-8.

[44] Dash BK, Achary PGR, Nayak NC. Dielectric relaxation behaviour of ethylene-vinyl acetateexfoliated graphene nanoplatelets $(\mathrm{xGnP})$ composites. Journal of Materials Science: Materials in Electronics. 2015;26(9):7244-54.

[45] Foulger SH. Reduced percolation thresholds of immiscible conductive blends of poly (ethylene-covinyl acetate) and high density polyethylene. Electrical Insulation and Dielectric Phenomena, 1998 Annual Report Conference on: IEEE; 1998. p. 282-7.

[46] Zhang MQ, Yu G, Zeng HM, Zhang HB, Hen YH. Two-step percolation in polymer blends filled with carbon black. Macromolecules. 1998;31(19):6724-6.

[47] Kurusu RS, Helal E, Moghimian N, David E, Demarquette N. The Role of Selectively Located Commercial Graphene Nanoplatelets in the Electrical Properties, Morphology, and Stability of EVA/LLDPE Blends. Macromolecular Materials and Engineering. 2018:1800187.

[48] Zhu G-J, Ren P-g, Guo H, Jin Y-L, Yan D-X, Li Z-M. Highly Sensitive and Stretchable Polyurethane Fiber Strain Sensors with Embedded Silver Nanowires. ACS Applied Materials \& Interfaces. 2019.

[49] Ren F, Li Z, Xu L, Sun Z, Ren P, Yan D, et al. Large-scale preparation of segregated PLA/carbon nanotube composite with high efficient electromagnetic interference shielding and favourable mechanical properties. Composites Part B: Engineering. 2018;155:405-13.

[50] Shokri E, Yegani R, Heidari S, Shoeyb Z. Effect of PE-g-MA compatibilizer on the structure and performance of HDPE/EVA blend membranes fabricated via TIPS method. Chem Eng Res Des. 2015;100:237-47.

[51] Noh YJ, Joh H-I, Yu J, Hwang SH, Lee S, Lee CH, et al. Ultra-high dispersion of graphene in polymer composite via solvent free fabrication and functionalization. Scientific reports. 2015;5:9141.

[52] Meszlényi G, Körtvélyessy G. Direct determination of vinyl acetate content of ethylene-vinyl acetate copolymers in thick films by infrared spectroscopy. Polym Test. 1999;18(7):551-7.

[53] Hojjat A, Mahmood B. Effect of EVA content upon the dielectric properties in LDPE-EVA Films. International Journal of Engineering Research. 2015;4(2):69-72.

[54] Badakhsh A, Lee Y-M, Rhee KY, Park CW, An K-H, Kim B-J. Improvement of thermal, electrical and mechanical properties of composites using a synergistic network of length controlled-CNTs and graphene nanoplatelets. Composites Part B: Engineering. 2019;175:107075. 
[55] Stark W, Jaunich M. Investigation of ethylene/vinyl acetate copolymer (EVA) by thermal analysis DSC and DMA. Polym Test. 2011;30(2):236-42.

[56] Sabet M, Soleimani H, Hosseini S. Effect of addition graphene to ethylene vinyl acetate and lowdensity polyethylene. Journal of Vinyl and Additive Technology. 2018;24:E177-E85.

[57] Mofokeng TG, Ray SS, Ojijo V. Influence of Selectively Localised Nanoclay Particles on NonIsothermal Crystallisation and Degradation Behaviour of PP/LDPE Blend Composites. Polymers (Basel). 2018;10(3):245.

[58] Gil-González E, Perejón A, Sanchez-Jimenez PE, Medina-Carrasco S, Kupčík J, Šubrt J, et al. Crystallization kinetics of nanocrystalline materials by combined X-ray diffraction and differential scanning calorimetry experiments. Crystal Growth \& Design. 2018;18(5):3107-16.

[59] Xu P, Luo X, Zhou Y, Yang Y, Ding Y. Enhanced cold crystallization and dielectric polarization of PLA composites induced by P [MPEGMA-IL] and graphene. Thermochim Acta. 2017;657:156-62.

[60] Tarani E, Wurm A, Schick C, Bikiaris D, Chrissafis K, Vourlias G. Effect of graphene nanoplatelets diameter on non-isothermal crystallization kinetics and melting behavior of high density polyethylene nanocomposites. Thermochim Acta. 2016;643:94-103.

[61] Faker M, Aghjeh MR, Ghaffari M, Seyyedi S. Rheology, morphology and mechanical properties of polyethylene/ethylene vinyl acetate copolymer (PE/EVA) blends. Eur Polym J. 2008;44(6):1834-42.

[62] Dalai S, Wenxiu C. Radiation effects on LDPE/EVA blends. J Appl Polym Sci. 2002;86(5):1296-302.

[63] Youssef HA, Senna MM, Eyssa HM. Characterization of LDPE and LDPE/EVA blends crosslinked by electron beam irradiation and foamed with chemical foaming agent. Journal of Polymer Research. 2007;14(5):351-7.

[64] Tang M, Qi F, Chen M, Sun Z, Xu Y, Chen X, et al. Synergistic effects of ammonium polyphosphate and red phosphorus with expandable graphite on flammability and thermal properties of HDPE/EVA blends. Polym Adv Technol. 2016;27(1):52-60.

[65] Thinh PX, Basavaraja C, Kim KI. Fabrication and characterization of honeycomb-patterned film from poly ( $\varepsilon$-caprolactone)/poly ((R)-3-hydroxybutyric acid)/reduced graphene oxide composite. Polym J. 2013;45(10):1064.

[66] Zhang C, Li A, Zhao YH, Bai SL, Zhang YF. Thermal, electrical and mechanical properties of graphene foam filled poly (methyl methacrylate) composite prepared by in situ polymerization. Composites Part B-Engineering. 2018;135:201-6.

[67] Azizi S, Azizi M, Sabetzadeh M. The Role of Multiwalled Carbon Nanotubes in the Mechanical, Thermal, Rheological, and Electrical Properties of PP/PLA/MWCNTs Nanocomposites. Journal of Composites Science. 2019;3(3):64.

[68] Paredes J, Villar-Rodil S, Martínez-Alonso A, Tascon J. Graphene oxide dispersions in organic solvents. Langmuir. 2008;24(19):10560-4.

[69] Peon J, Vega J, Del Amo B, Martınez-Salazar J. Phase morphology and melt viscoelastic properties in blends of ethylene/vinyl acetate copolymer and metallocene-catalysed linear polyethylene. Polymer. 2003;44(10):2911-8.

[70] Carastan DJ, Demarquette NR. Microstructure of nanocomposites of styrenic polymers. Macromolecular symposia: Wiley Online Library; 2006. p. 152-60.

[71] Davachi SM, Heidari BS, Sahraeian R, Abbaspourrad A. The effect of nanoperlite and its silane treatment on the crystallinity, rheological, optical, and surface properties of polypropylene/nanoperlite nanocomposite films. Composites Part B: Engineering. 2019;175:107088.

[72] Krishnamoorti R, Giannelis EP. Rheology of end-tethered polymer layered silicate nanocomposites. Macromolecules. 1997;30(14):4097-102.

[73] Utracki L. On the viscosity-concentration dependence of immiscible polymer blends. J Rheol. 1991;35(8):1615-37. 
Supplementary electronic materials

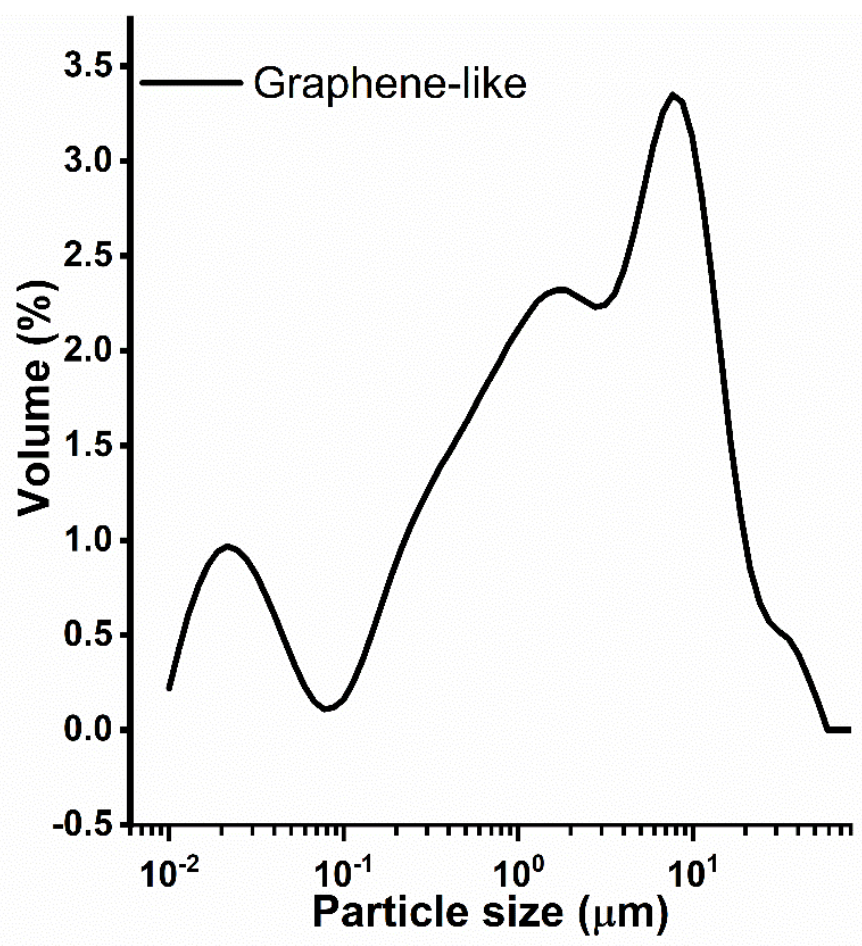

Figure S1. Particle size distribution of clay graphene-like. 